\title{
Translating knowledge into action to prevent pediatric and adolescent diabesity: a meeting report
}

This article was published in the following Dove Press journal:

Adolescent Health, Medicine and Therapeutics

\author{
Janatani Balakumaran 1,2,* \\ Yun-Ya Kao ${ }^{1,2, *}$ \\ Kuan-Wen Wang ${ }^{1,2}$ \\ Gabriel M Ronen ' \\ James MacKillop ${ }^{3}$ \\ Lehana Thabane ${ }^{1,4-7}$ \\ M Constantine Samaan ${ }^{1,2,4}$ \\ 'Department of Pediatrics, McMaster \\ University, Hamilton, Ontario, Canada; \\ ${ }^{2}$ Division of Pediatric Endocrinology, \\ McMaster Children's Hospital, Hamilton, \\ Ontario, Canada; ${ }^{3}$ Department of \\ Psychiatry and Behavioural \\ Neurosciences, Faculty of Health \\ Sciences, Peter Boris Centre for \\ Addictions Research, McMaster \\ University/St. Joseph's Healthcare \\ Hamilton, Hamilton, Ontario, Canada; \\ ${ }^{4}$ Department of Health Research \\ Methods, Evidence and Impact, McMaster \\ University, Hamilton, Ontario, Canada; \\ ${ }^{5}$ Department of Anesthesia, McMaster \\ University, Hamilton, Ontario, Canada; \\ ${ }^{6}$ Centre for Evaluation of Medicines, St. \\ Joseph's Health Care, Hamilton, Ontario, \\ Canada; ${ }^{7}$ Biostatistics Unit, St Joseph's \\ Healthcare-Hamilton, Hamilton, Ontario, \\ Canada
}

*These authors contributed equally to this work

Correspondence: M Constantine Samaan Department of Pediatrics, McMaster University, Division of Pediatric

Endocrinology, McMaster Children's Hospital, 1280 Main Street West,

HSC-3A57, Hamilton, Ontario L8S 4KI, Canada

Tel +I $90552 \mid 2100$ ext. 75926

$\mathrm{Fax}+19053087548$

Email samaanc@mcmaster.ca
Background: The obesity and Type 2 Diabetes Mellitus (T2DM) rates are at an all-time high globally. This diabesity epidemic is increasingly impacting children and adolescents, and there is scarce evidence of interventions with favourable long-term outcomes.

Purpose: In order to understand the determinants of diabesity and how to address them, multiple stakeholders were invited to a meeting to discuss current state of knowledge and to help design a program to prevent pediatric and adolescent diabesity.

Participants and methods: The meeting was held at McMaster University on March 4th, 2015. The event involved presentations to deliver state-of-the-art knowledge about diabesity, and roundtable discussions of several domains including nutrition, physical activity, sleep, and mental health. Discussion transcripts were analyzed using NVivo.

Results: Forty-nine participants took part in the workshop. They included clinical healthcare professionals, public health, Aboriginal Patient Navigator, research scientists, students, and patients with family members. A total of 628 reference counts from the roundtable discussions were coded under 20 emerging themes. Participants believed that the most important elements of the program involve the provision of knowledge and education, family involvement, patient motivation, location of program delivery, and use of surveys and questionnaires for outcome measurement.

Conclusion: Effective pediatric and adolescent diabesity prevention programs should be conceptualized by multidisciplinary stakeholders and embrace the complexity of diabesity with multiprong interventions. This meeting provided a framework for developing such interventions.

Keywords: diabesity, meeting, pediatric, adolescent, obesity, pediatric type 2 diabetes mellitus

\section{Introduction}

Obesity rates in children and adolescents have tripled over the past 30 years, and it is estimated that nearly 42 million preschool-aged children are overweight or obese globally. ${ }^{1}$ Childhood and adolescent obesity is a strong predictor of adult obesity, ${ }^{2-5}$ and is a significant risk factor for type 2 diabetes mellitus (T2DM), an increasingly prevalent disorder in pediatric clinical practice. $^{3,6,7}$

The association between obesity and T2DM is referred to as diabesity. ${ }^{8-10}$ Diabesity can be associated with significant comorbidities including hypertension, dyslipidemia, fatty liver disease, cardiovascular events, cerebrovascular disease, and obstructive sleep apnea. ${ }^{11}$ These comorbid associations of diabesity can lower the quality of life, and may shorten the life expectancy of this generation of children. ${ }^{12,13}$ 
The etiology of diabesity is complex and includes genetic factors, epigenetic phenomena, as well as lifestyle and environmental factors including poor food quality, sedentary behaviours, technology use and stress. ${ }^{14}$ How these factors interact in a given person to affect the risk of diabesity is poorly understood despite significant research efforts. Lifestyle interventions and pharmacological treatments have proven to be of limited success or carry unacceptable side effects for the latter, and drastic treatments including bariatric surgery carry a risk for complications and have unknown long-term effects in youth. ${ }^{15-18}$

The multifactorial roots of the diabesity epidemic and the high failure rates of current non-surgical approaches to achieve favourable long-term outcomes require new thinking to create effective, feasible, engaging, and relevant lifestyle interventions to prevent its occurrence. ${ }^{19}$ The engagement of multiple stakeholders to help design, implement, and evaluate novel interventions is critical to ensure successful outcomes. To this end, we invited multiple stakeholders to a meeting to help envision a program to prevent childhood and adolescent diabesity.

\section{Methods}

\section{Setting and participants}

The meeting was held at McMaster University on March 4th, 2015. We used LimeSurvey ${ }^{\mathrm{TM}}$ to register participants. Stakeholders including parents, children and youth, healthcare and public health professionals, students, administrators, and researchers were invited to participate.

The meeting included two parts. In the first part, presentations by healthcare experts focused on current understanding of the pathways to diabesity. These presentations included the consideration of themes as to whether diabesity is an addiction to food, and whether obesity and T2DM are disabilities. ${ }^{20,21}$ Finally, there was a focused review on the lifestyle factors and mechanisms driving childhood and adolescent diabesity.

In the second part, roundtable discussions took place to design the diabesity prevention program. The discussions involved four domains including nutrition, physical activity (PA), sleep, and mental health with two station runs per theme. There were 6-7 participants in each group, with two researchers facilitating and documenting the discussions per group.

Three open-ended questions were posed to participants:
1. What elements should be included in the design of the intervention?

2. How should this intervention be presented/ implemented?

3. What outcomes should be measured and how?

\section{Data analysis}

The data were analyzed using NVivo for Mac software (version 11.0, QRS International). ${ }^{22}$ Codes were extracted from the transcriptions; a code consists of a word or excerpt of qualitative data that shares collective meaning with other pieces of data. ${ }^{23}$ The collective categories of codes constitute themes, with some themes further divided into sub-themes.

The coding process consisted of five stages, and themes were organized in a hierarchy as they emerged using an inductive approach. ${ }^{24}$ The hierarchy of themes was based on reference counts for each theme.

The process involved the following steps:

1. The researchers read the transcripts and familiarized themselves with the data.

2. Excerpts and words were coded under preliminary themes. Themes were termed based on keywords in the documents and summaries of ideas from the data.

3. Transcripts were used to generate new subthemes. New pieces of coded data were compared against the existing data at the node to ensure consistency.

Excerpts and words were coded under a new subtheme if it could be a distinct and relevant category under an existing theme.

4. Transcripts were analyzed using the coding stripes function, with each coding stripe coloured to represent a specific node.

5. The coding was audited in reverse by reading through each node to ensure that the coded references were relevant. In this stage, new sub-themes were added and the hierarchy was reorganized as needed. Whenever a new node was added, a detailed text search query was run to find all sources containing the specified keywords.

\section{Results}

Forty-nine participants attended the workshop $(n=12$ female). This group included 16 healthcare professionals (clinical/laboratory specialists $(n=4)$, registered dieticians 
$(n=4)$, registered nurses $(n=3)$, patient navigator $(n=1)$, physicians $(n=3)$, social worker $(n=1))$, public healthbased dietician $(n=1)$, research scientists/faculty $(n=4)$, students $(n=26)$, and patient with family members $(n=2)$.

Twenty themes were extracted and categorized into the four domains including nutrition, physical activity, sleep, and mental health. At the beginning of the coding process, the themes were divided into three components including process and success elements, intervention content, and outcome measurement.

A total of 628 data points was coded under the themes (Table 1). Given that the NVivo software provides a reference count for every theme, a semi-quantitative approach was chosen to present and interpret the data. The number of codes under each theme is presented in Table 2. These values were used to explain the hierarchy of the theme and distribution of reference counts among domains. The themes are reproted in the order of frequency but also in terms of their importance even if they were not frequently noted.

\section{Nutrition \\ Process \& success elements}

The nutrition groups valued educating the entire family about healthy eating and parental monitoring of their children's diet and involving children in meal preparation $(n=13)$ and grocery shopping $(n=17)$.

The groups noted that the content and presentation of information should be based on the child's capacity to learn $(n=6)$, and that educating children and adolescents

Table I Description of the overarching components and the themes that fall under each component

\begin{tabular}{|c|c|c|}
\hline Component & Theme & Description \\
\hline $\begin{array}{l}\text { Process and } \\
\text { Success Elements }\end{array}$ & $\begin{array}{l}\text { Familial involvement } \\
\text { Motivation } \\
\text { Choice } \\
\text { Age-appropriateness } \\
\text { Barriers to success } \\
\text { Routines } \\
\text { Existing programs } \\
\text { Peer involvement }\end{array}$ & $\begin{array}{l}\text { Ways that the family should be involved in implementing healthy lifestyle changes. } \\
\text { Methods of motivating children, adolescents, and parents to participate in the program and } \\
\text { implement long-term healthy lifestyle changes. } \\
\text { Ways to allow youth to participate in decision-making and avoid restrictive and instructive approaches. } \\
\text { The provided information and recommendations should be tailored to the child or adolescent's } \\
\text { age and developmental stage. } \\
\text { The potential barriers that may prevent the achievement of successful outcomes for youth and } \\
\text { families. } \\
\text { The importance of developing routine behaviors in order to achieve and sustain positive outcomes. } \\
\text { Elements of existing programs and techniques that have been successful in achieving particular } \\
\text { outcomes and could be replicated in this program } \\
\text { The importance of involving peers for support, sharing information, collaboration, and feedback } \\
\text { provision. }\end{array}$ \\
\hline $\begin{array}{l}\text { Intervention } \\
\text { Content }\end{array}$ & $\begin{array}{l}\text { Knowledge and } \\
\text { education } \\
\text { Skill-building } \\
\text { Personalization } \\
\text { De-stigmatization } \\
\text { Simplicity } \\
\text { Location } \\
\text { Technological } \\
\text { Non-technological }\end{array}$ & $\begin{array}{l}\text { Information provided in the module should impart up to date knowledge to educate youth, } \\
\text { parents, and teachers. } \\
\text { Information provided should build skills that will facilitate the sustenance of a healthy lifestyle for } \\
\text { youth and families. } \\
\text { The information provided should meet the needs, age, gender, culture, circumstances, and } \\
\text { personal preferences of the individual child or adolescent. } \\
\text { The information provided should reduce the stigma, stereotypes, and bullying associated with } \\
\text { obesity and T2DM. } \\
\text { The information should be presented in a simple and understandable manner. } \\
\text { The location where the module should be implemented, including schools, community,clinics, and } \\
\text { online. } \\
\text { Online and offline technology, including applications, should be used to present the information of the } \\
\text { modules. } \\
\text { Non-online means should be used to present the information. }\end{array}$ \\
\hline $\begin{array}{l}\text { Outcome } \\
\text { measurement }\end{array}$ & $\begin{array}{l}\text { Surveys/questionnaires } \\
\text { Other progress- } \\
\text { measurement tools } \\
\text { Tests/Quizzes } \\
\text { Interviews }\end{array}$ & $\begin{array}{l}\text { Surveys and questionnaires could be used to measure progress. } \\
\text { Various other tools, including technological tools, could be used to measure the program's outcomes. } \\
\text { Tests and quizzes could be used to measure changes in knowledge for children, adolescents and } \\
\text { parents. } \\
\text { Interviews could be a useful tool for evaluating outcomes. }\end{array}$ \\
\hline
\end{tabular}


Table 2 Distribution of reference counts from roundtable discussions

\begin{tabular}{|c|c|c|c|c|c|c|}
\hline Component & Theme & Nutrition & Physical activity & Sleep & Mental health & Total \\
\hline \multirow[t]{9}{*}{ Process and Success Elements } & Familial involvement & 13 & 12 & 28 & 11 & 64 \\
\hline & Motivation & 11 & 16 & 11 & 19 & 57 \\
\hline & Choice & 17 & 7 & 3 & 2 & 29 \\
\hline & Age-appropriateness & 6 & 3 & 5 & 9 & 23 \\
\hline & Barriers to success & 1 & 4 & 7 & 10 & 22 \\
\hline & Routine & I & I & 10 & 0 & 12 \\
\hline & Existing programs & 2 & 2 & 2 & 5 & 11 \\
\hline & Peer involvement & 0 & 2 & 0 & 2 & 4 \\
\hline & Total & 51 & 47 & 66 & 58 & 222 \\
\hline \multirow[t]{14}{*}{ Intervention Content } & Knowledge and education & 15 & 7 & 23 & 21 & 66 \\
\hline & Personalization & 3 & 14 & 11 & 10 & 38 \\
\hline & Skill building & 7 & 0 & 4 & 16 & 27 \\
\hline & De-stigmatization & 0 & 4 & 0 & 10 & 14 \\
\hline & Simplicity & 4 & 0 & 0 & 4 & 8 \\
\hline & Location & 7 & 15 & 7 & 19 & 48 \\
\hline & - School & 7 & 11 & 4 & 15 & 37 \\
\hline & - Community & 0 & 4 & 2 & 3 & 9 \\
\hline & - Clinic & 0 & 0 & 1 & 1 & 2 \\
\hline & Technological & 14 & 7 & 7 & 6 & 34 \\
\hline & - Apps & 9 & 0 & I & 2 & 12 \\
\hline & Non-technological & 15 & 3 & 1 & 4 & 23 \\
\hline & - Non-technological games & 7 & 1 & 0 & 0 & 8 \\
\hline & Total & 88 & 66 & 61 & 111 & 326 \\
\hline \multirow[t]{7}{*}{ Outcome measurement } & Surveys and questionnaires & 6 & 1 & 19 & 15 & $4 I$ \\
\hline & Other progress tools & 3 & 4 & 9 & 2 & 18 \\
\hline & - Technological tools & 0 & 2 & 6 & 1 & 9 \\
\hline & Tests/quizzes & 4 & 0 & 2 & 0 & 6 \\
\hline & Interviews & I & 0 & 2 & 3 & 6 \\
\hline & Total & 14 & 7 & 38 & 21 & 80 \\
\hline & Total for all components & 130 & 120 & 165 & 190 & 628 \\
\hline
\end{tabular}

about food and health should not focus on the harmful consequences of unhealthy nutrition $(n=1)$. Having access to healthy foods at home and at school $(n=17)$ was considered important.

Participants believed that peer motivation through class efforts to eat healthier would be effective $(n=11)$, and that healthy eating should become a routine $(n=1)$. It was noted that the need for peer conformation might force youth to purchase meals at school instead of bringing homemade meals $(n=1)$. An existing approach was highlighted in which a school-based healthy food challenge involved teachers evaluating homemade lunches and assigning positive scores to healthier foods $(n=2)$.

\section{Intervention content}

The nutrition groups recognized the importance of education regarding the appropriate quantity and quality of foods, food sources, method of preparation, food label reading, healthy eating habits, and healthy recipes $(n=15)$. Participants noted the need for a diverse approach that is sensitive to culture, socioeconomic status, and ethnicity $(n=3)$

Participants highlighted the need for building longterm healthy eating skills by teaching children and adolescents to prepare meals and shop for healthy foods. The groups also felt that clear information on what constitutes healthy foods should be provided $(n=4)$. Canada's Food Guide, for instance, was considered too detailed for children to use. ${ }^{25}$

The nutrition groups suggested using digital online and device-based applications and to gamify some of the information about food composition, portion size, and the effects of various macronutrients on health $(n=14$ for technological tools, $\mathrm{n}=9$ for applications). Non-technological 
tools included visually appealing handouts and booklets containing games, as well as school challenges involving healthy lunch preparation $(n=15$ for non-technological, $\mathrm{n}=7$ for non-technological games, $\mathrm{n}=7$ for school).

\section{Outcome measurement}

The nutrition groups believed that surveys and questionnaires could be administered to children and adolescents, parents, and teachers to record food intake, frequency, timing, eating behaviours, and meal planning $(n=6)$. Other strategies to measure change in diet including dinner diaries and photo journaling $(n=3)$. Participants also believed that children and adolescents could write quizzes or standardized tests before and after implementation or throughout the program to determine changes in knowledge $(n=4)$. Family conversations about attitudes to food could help gain insight into changes in outcomes $(n=1)$.

\section{Physical activity (PA) \\ Process \& success elements}

The PA groups suggested that the child's family must be informed and encouraged to engage in recommended levels of activity, control their children's screen time, and have them partake in activity with the entire family $(n=12)$. Participants also suggested motivating children and adolescents to engage in PA through group/class efforts to destigmatize diabesity $(n=16)$, and allowing children and adolescents to set personalized goals and choose activities in schools and communities $(n=7)$. In addition, age-appropriateness of a given activity needed be taken into consideration $(n=3)$.

Participants were also concerned about barriers to success, including misconceptions about the duration and intensity of recommended or needed PA and the poor enforcement of daily PA at schools $(n=4)$. To ensure success, the groups identified peer support as a motivation to exercise $(n=2)$, and that PA should become a routine to sustain long-term changes $(n=1)$. The groups identified Jump Rope for Heart, ${ }^{26}$ a schoolbased fundraiser where children jump rope for charity, and $\mathrm{Wii}^{\mathrm{TM}}$ fitness games as potential interventions that may be adopted $(n=2)$, although it was acknowledged that the evidence for the effectiveness of the latter option is not conclusive.

\section{Intervention content}

The PA groups sought an intervention that will provide information about age-appropriate levels of activity including duration, type, and intensity and to highlight the benefits of PA $(n=7)$. Participants also encouraged personalizing the program to meet the goals, strengths, and preferences of children and adolescents $(n=14)$ and identified the need to reduce the stigma surrounding PA in those with diabesity through education $(n=4)$. Fostering inclusivity in schools and within online communities was proposed to be important ( $n=11$ for school, $\mathrm{n}=4$ for community). Interestingly, the groups proposed encouraging PA using online games, Wii Fit ${ }^{\mathrm{TM}}$, websites, and online videos ( $n=7$ for technological), again while acknowledging that the evidence base for benefits is very limited. Participants also suggested providing activity documentation and listings charts, the creation of newsletters, and a 20/20 challenge, which is a program that involves promoting physical literacy through 20 minutes of physical activity every day for 20 weeks ( $n=3$ for nontechnological, $\mathrm{n}=1$ for non-technological games). ${ }^{27}$

\section{Sleep}

\section{Process \& success elements}

Participants valued educating the family about sleep hygiene and creating an environment conducive to highquality sleep ( $n=28)$. Motivating youth and focusing on the effects of sleep on individually important outcomes using interactive videos and rewarding good sleep routines were also noted $(n=11)$. The groups proposed allowing children and adolescents to choose a preferred calming activity before sleep $(n=3)$, as the lack of these activities or participating in stimulating activities before sleep can affect sleep quality $(n=7)$. The proposed factors of poor sleep quality that were considered included screen time, noise, room colour, family stresses, poor time-management skills, and undervaluing sleep.

Participants noted that the content of a sleep education program should be age-appropriate $(n=5)$, and should involve information about establishing routines with consistent sleep-related household rules $(n=10)$. It was proposed that existing school-based health education programs should incorporate sleep into the curriculum using guided imagery for meditation and relaxation $(n=2)$.

\section{Intervention content}

The sleep groups valued education regarding the appropriate duration, quality, and benefits of sleep. Strategies for sleep optimization through sleep hygiene measures, reducing sleep latency, the effects of sleep deprivation on daily 
activities, and the effects of diet and PA on sleep were also considered important $(\mathrm{n}=23)$.

Encouraging children and adolescents to identify factors that lead to inadequate sleep $(n=11)$ and helping them with skill-building was considered essential $(n=4)$. Some suggestions included planning a routine before bedtime to help improve sleep quality. The groups recommended incorporating sleep education in schools through the curriculum and guest speakers $(n=11)$, as well as written and digitally-based information provided through family physician offices $(n=1)$, community-based recreational centers, and community clinic centers $(n=2)$ to educate youth and families about sleep hygiene.

Interactive online videos, Fitbits ${ }^{\mathrm{TM}}$, and applications on electronic devices were proposed to inform children about their sleep ( $\mathrm{n}=7$ for technological, $\mathrm{n}=1$ for applications).

\section{Outcome measurement}

The groups believed that surveys and questionnaires administered to children, adolescents, parents, and teachers could effectively measure sleep duration, alertness, and energy levels $(n=19)$. Participants also suggested that sleep hygiene and its effects could be measured using reflections, tracking sheets, and journaling $(n=9)$, while Fitbits ${ }^{\mathrm{TM}}$ and sleep tracking applications were seen as tools that provide additional quantitative data to assess sleep $(n=6)$.

Incorporating discussions about sleep pattern and attentiveness in class into parent-teacher interviews $(n=2)$ and using quizzes and tests to evaluate knowledge of sleep hygiene $(n=2)$ were considered potential educational pathways around this important component of health interventions.

\section{Mental health}

\section{Process \& success elements}

The mental health groups believed that parents should be educated on the impact of stress and mental health on diabesity and vice versa $(n=11)$. Discussing emotional health during parent-teacher interviews were also encouraged. Motivational strategies that focus on creating a healthy mind including the creation of a safe space in the classroom, peer-to-peer sharing and mentoring, involving celebrities in disseminating information, and using tangible rewards $(n=19)$.

Participants also described the importance of allowing children and adolescents to choose their preferred stress- relief method $(n=2)$. It was noted that the age-dependent nature of stress and mental health concerns requires appropriate information regarding stress and coping strategies $(n=9)$. Potential barriers to addressing mental health concerns in youth included stigma, low self-esteem, familial stress, low socioeconomic status, family resources, and relationship dynamics were all considered important aspects to tackle $(\mathrm{n}=10)$.

Participants considered bullying awareness weeks in schools as well as community programs that provide resources regarding stress management as potential approaches to address mental health needs. In addition, participants described potentially useful models including Dialectical Behavioral Therapy (DBT) Diary Cards and Skills Coaches, an application that functions as a diary to $\log$ skills and goals $(n=5) .^{28}$

It was also suggested that peers could share their challenges, coping methods, and provide feedback to each other $(n=2)$.

\section{Intervention content}

The mental health groups noted that the information provided should be personalized $(n=10)$, and that education should highlight how mental health symptoms manifest at different ages, the connection between mental health and metabolic health, and strategies to recognize and manage mental health concerns $(n=21)$. Participants further identified the importance of educating teachers and incorporating awareness programs into school curricula $(n=21)$. Participants valued the reduction of stigmatization $(\mathrm{n}=10)$, and implementing awareness campaigns and bullying prevention programs in schools ( $\mathrm{n}=3$ for community, $\mathrm{n}=15$ for school).

Participants emphasized the need for children and adolescents, parents, and teachers to learn to recognize stress in youth with diabesity $(\mathrm{n}=16)$, and to simplify the understanding of symptoms to help identify individuals at risk $(n=4)$. Participants suggested incorporating anti-bullying messages and mental health awareness into commercials, television shows, and websites $(n=6)$, using online chat rooms and phone support lines $(n=6)$, and the DBT Diary Card and Skills Coaches or similar applications were also considered. The distribution of handouts and booklets about stress during encounters with the healthcare system and mental health coping strategies and resources could help youth recognize and manage these problems $(n=4$ for non-technological, $\mathrm{n}=1$ for clinics). 


\section{Outcome measurement}

Groups believed that surveys and questionnaires could be useful tools for measuring stress levels, quality of life, body image, and mood $(n=15)$. The groups also suggested journaling $(n=2)$ to measure changes in emotional state and applications $(\mathrm{n}=1)$ to record changes in stress levels. It was noted that interviews with children, parents, and teachers could help measure outcomes $(n=3)$.

\section{Creation of the intervention model}

Based on the information provided by stakeholders, a model was created to depict the design of the program to prevent diabesity in children and adolescents (Figure 1). The child and youth are at the center of a multi-stakeholder partnership including the family, school, community, and policy makers with government input. The model emphasizes the importance of the elements of healthy living suggested by participants, namely nutrition, PA, sleep, and mental health.

Recognizing the elements of success is crucial for the successful building of the model. This requires the help of families and parents for children and adolescents to achieve expertise on themes such as motivation and how the child deals with barriers that affect healthy behaviours.

Delivering this intervention will equip the child and adolescent with relevant knowledge and personalizes preventative approaches. Using both technological and non-technological tools will help facilitate the delivery and evaluation of knowledge acquisition and outcomes.

The integration of the themes and pillars defined through the input of stakeholders in this model is needed to help the implementation of successful interventions to mitigate diabesity.

\section{Discussion}

The diabesity epidemic in adults is driving a surge in noncommunicable chronic diseases including cardiovascular disease, hypertension, and stroke. As childhood and adolescent obesity will likely translate to obesity during adulthood, there is an urgent need to define effective interventions to prevent childhood and adolescent obesity and T2DM and to lessen their impact on the individual,

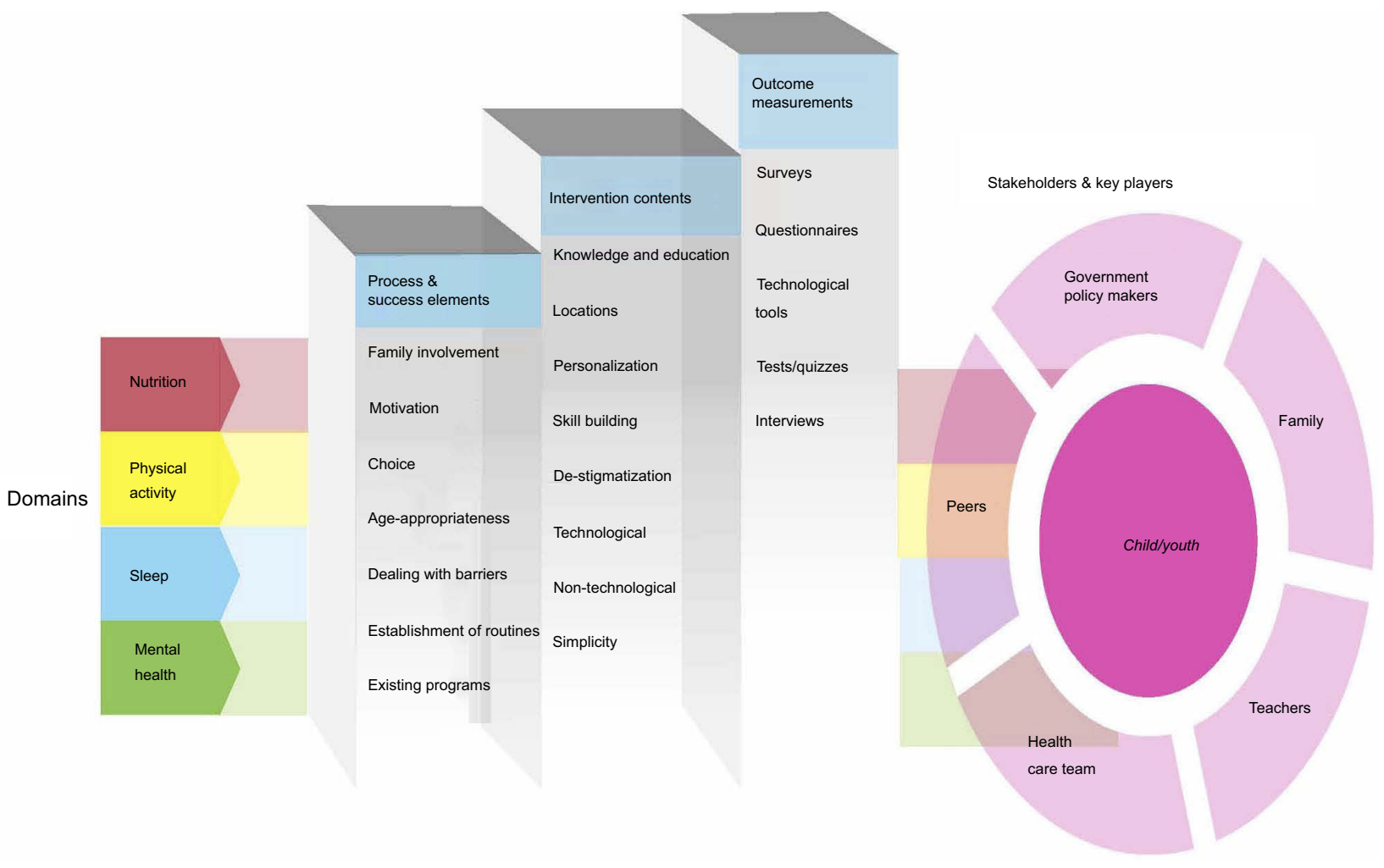

Figure I The model of childhood and adolescent diabesity prevention program. The model is broken down into two major sections, with one section being the steps of building the model and another involving the major stakeholders that are responsible for building it. The model is represented as a staircase that builds on a series of steps. Each step represents one of the overarching components and includes the hierarchy of themes that fall under that component, with the most cited theme being on top. The four domains are integrated into both sections as they are discussed as being significant throughout the construction of the model. Please refer to table I for the definition of the components, domains, and themes. The major stakeholders and key players include parents, government/policy makers, teachers, health care teams, and peers, with the child being at the centre of action of the group. 
community, society, and healthcare systems across the lifespan globally. ${ }^{29,30}$ While some of the existing literature supports the use of lifestyle interventions including school and community-based approaches to manage diabesity, the long-term success of these programs and their potential to modify future cardiometabolic outcomes is yet unclear. ${ }^{31,32}$ This suggests that the practicalities of the creation of successful programs that demonstrate long-term impact are still evolving.

While lifestyle interventions for adult T2DM prevention have yielded reasonably positive outcomes, ${ }^{33-37}$ the evidence for a successful program for preventing pediatric diabesity is very limited due to the relative novelty of diabesity in pediatric clinical practice. ${ }^{38-41}$ Furthermore, as $\mathrm{T} 2 \mathrm{DM}$ in youth is a strong predictor of adult diabesity, ${ }^{2-5}$ the prevention of pediatric diabesity can help children and adolescents avoid this chronic disease, which will improve their lifespan and quality of life. Thus, there is a dire need for the design of successful diabesity prevention programs and assessment of the elements required for sustained success of such programs.

Broader stakeholder involvement at the early development stages of the program, as proposed in our model, helps provide better guidance for the creation of a childhood and adolescent diabesity prevention program. This is concurrent with the realization that stakeholder-important outcomes are essential for the standardization and implementation of the intervention frameworks into practice. ${ }^{42,43}$ Current pediatric obesity prevention programs, however, tend to involve stakeholders late in the implementation stage $\mathrm{e}^{42}$ and this area of research and clinical care needs further development by advocating for patient-important outcomes to be included early in the process of designing these interventions.

Stakeholder diversity is crucial in the development of the diabesity prevention programs. Existing evidence suggests that the consultation and involvement of a variety of stakeholders in intervention design facilitates the development of comprehensive recommendations and intervention strategies. ${ }^{44}$ Parents are an important group, as they play a vital role in helping children and adolescents have a healthy lifestyle including healthy eating habits. ${ }^{45,46}$ Parental input allows the development of interventions that incorporate parental influences on their children's behaviour to maximize success. ${ }^{45}$ Consistent with this concept, participants in our study also highly valued the contribution of parents, with familial participation being one of the most cited theme from discussions.
Legislators and policymakers are another important group in designing and implementing interventions, but also in generalizing these interventions across the educational and healthcare systems. Decision-makers have unique insights into the logistics and cost of implementing interventions at local, regional, and national levels. Policymakers also may have a good understanding of engaging other relevant stakeholders to create public health policies that support prevention and intervention efforts. ${ }^{47-49}$ Indeed, stakeholder engagement has been shown to increase the interest of policymakers in implementing system-wide changes. ${ }^{49}$

The themes discussed by the stakeholders in our workshop were quite variable, but the most cited themes reflected what stakeholders valued most in an intervention.

One of the most cited elements was familial involvement, which is congruent with current literature supporting the involvement of families in pediatric obesity and T2DM prevention. $^{50-53}$ Programs that did not follow this approach have had limited success in these types of interventions. $^{54}$ We believe that the involvement of families and youth should be an early and consistent focus for diabesity prevention programs to understand patient- and family-important outcomes.

Not surprisingly, knowledge and education was a widely cited intervention content theme to help children and families develop healthy habits. Education regarding all four domains was popular among stakeholders.

There is limited literature exploring the connection between mental health, sleep, and diabesity prevention. ${ }^{55,56}$ These domains were highly valued by our participants, necessitating the integration of mental health and sleep education in our proposed prevention model.

Surveys and questionnaires were the most frequently suggested tools for outcome measurement including changes in dietary intake, activity levels, sleep, emotional state, socialization, stress levels, and quality of life. A wide variety of surveys and questionnaires exist in the literature that measure pediatric lifestyles. ${ }^{57-60}$ These surveys and questionnaires are effective and can be used as outcome measurement tools for this prevention program. ${ }^{57-60}$

The personalization of interventions has emerged as a consistent theme in our discussions. The personalized approach to healthcare has emerged as an important and controversial theme in medicine over the past few years. It has been heralded as ushering a new era of improved health outcomes, while being condemned for potentially 
widening the disparity in outcomes for those who can afford this approach versus those who cannot.

In addition, concerns have been raised about the potential for personalized medicine to divert resources from public health broad-reaching and effective approaches to more expensive and individualized care. ${ }^{61}$ While the debate continues on the merit of personalized medicine, the personalization of public health interventions has been discussed in some areas such as nutrition. ${ }^{62}$ The focus of personalized public health is on improving outcomes by merging several data sources including biological data from genotype and omics data as well as phenotypic variables, lifestyle preferences, societal values, and personal goals. ${ }^{62,63}$ Important questions remain about how to access and interpret personal data in this era of privacy and confidentiality awareness, who will create these interventions, the costs involved, and how to assess outcomes.

\section{Strengths \& limitations}

This work has several strengths. We created a platform for multiple stakeholders to participate in shaping the agenda of the program. In addition, recognizin that most clinical care programs do not start with involving patients and parents in the design of the program, we sought to involve stakeholders early on in the development of the program. While a small pool of patient and family members attended the meeting, future events need to engage more patients and families to gain further insights into the creation of pathways to best care.

One limitation is that while school-based interventions were highly encouraged, no representatives from schools were available to attend the discussions, and this needs to be addressed in future workshops.

The findings from this meeting produced themes that needs incorporation into the childhood diabesity prevention program. Future programs should be developed in different settings to increase the representation of stakeholders from different domains eg school. Once the findings of the meeting are incorporated into the development of the prevention program, follow-up investigations must be performed to determine the long-term effectiveness of the programs and areas for improvement to maximize impact.

\section{Conclusion}

In summary, this meeting sought input of stakeholders to develop a diabesity prevention program. Nutrition, physical activity, sleep, and mental health are interconnected determinants of diabesity that were targeted to create the intervention. The importance of sleep and mental health in the development and progression of diabesity were noted to be undervalued in current programs but were highly valued by participants. These ideas allowed the development of a child- and family-centered, comprehensive, and personalized childhood diabesity prevention program model.

\section{Author contributors}

All authors contributed to data analysis, drafting or revising the article, gave final approval of the version to be published, and agree to be accountable for all aspects of the work.

\section{Acknowledgment}

This meeting conduct used funds from educational grants from Eli Lilly and Sanofi. The funders were not involved in the conception of meeting idea, research questions definition, design, methods, conduct, analysis, interpretation, model creation, or the writing or review of the manuscript.

\section{Disclosure}

The authors report no conflicts of interest in this work.

\section{References}

1. World Health Organization (WHO). Childhood overweight and obesity. Available from: http://www.who.int/dietphysicalactivity/child hood/en/. Accessed August 8, 2019.

2. Wilfley DE, Kass AE, Kolko RP. Counseling and behavior change in pediatric obesity. Pediatr Clin North Am. 2011;58(6):1403-24, x. doi:10.1016/j.pcl.2011.09.014

3. Samaan MC, Valencia M, Cheung C, Wilk B, Lau K, Thabane L. Design, implementation, and evaluation of a pediatric and adolescent type 2 diabetes management program at a tertiary pediatric center. $J$ Multidiscip Healthc. 2014;7:321. doi:10.2147/JMDH.S46910

4. Biro FM, Wien M. Childhood obesity and adult morbidities. Am J Clin Nutr. 2010;91(5):1499S-505S. doi:10.3945/ajen.2010.28701B

5. Simmonds M, Llewellyn A, Owen C, Woolacott N. Predicting adult obesity from childhood obesity: a systematic review and meta-analysis. Obesity Rev. 2016;17(2):95-107. doi:10.1111/obr.12334

6. Zeitler P, Fu J, Tandon N, et al. Type 2 diabetes in the child and adolescent. Pediatr Diabetes. 2014;15(Suppl 20):26-46. doi:10.1111/ pedi. 12179

7. Goran MI. Metabolic precursors and effects of obesity in children: a decade of progress, 1990-1999. Am J Clin Nutr. 2001;73(2):158-171. doi:10.1093/ajen/73.2.158

8. Astrup A, Finer N. Redefining type 2 diabetes:'diabesity'or 'obesity dependent diabetes mellitus'? Obesity Rev. 2000;1(2):57-59.

9. Astrup A, Finer N, Redefining Type 2 diabetes: 'Diabesity' or 'Obesity Dependent Diabetes Mellitus'?. Obesity Reviews. 2000:1(2):57-59.

10. Zimmet P, Alberti KG, Shaw J. Global and societal implications of the diabetes epidemic. Nature. 2001;414(6865):782-787. 
11. Hamman RJ, Bell RA, Dabelea D et al. The SEARCH for Diabetes in Youth Study: Rationale, Findings, and Future Directions. Diabetes Care, 2014;37(12):3336-3344.

12. Pulgaron ER. Childhood obesity: a review of increased risk for physical and psychological comorbidities. Clin Ther. 2013;35(1): A18-A32. doi:10.1016/j.clinthera.2012.12.014

13. Kosti RI, Panagiotakos DB. The epidemic of obesity in children and adolescents in the world. Cent Eur J Public Health. 2006;14(4):151-159.

14. Kumar N, Puri N, Marotta F, et al. Diabesity: an epidemic with its causes, prevention and control with special focus on dietary regime. Funct Foods Health Dis. 2017;7(1):1-16. doi:10.31989/ffhd.v7i1.280

15. Kelly AS, Barlow SE, Rao G, et al. Severe obesity in children and adolescents: identification, associated health risks, and treatment approaches. Circulation. 2013;128(15):1689-1712. doi:10.1161/ CIR.0b013e 3182a5cfb3

16. Moya M. An update in prevention and treatment of pediatric obesity. World J Pediatr. 2008;4(3):173. doi:10.1007/s12519-008-0033-7

17. Mitchell PB, Morris MJ. Depression and anxiety with rimonabant. Lancet. 2007;370(9600):1671-1672. doi:10.1016/S0140-6736(07)61705-X

18. Treadwell JR, Sun F, Schoelles K. Systematic review and metaanalysis of bariatric surgery for pediatric obesity. Ann Surg. 2008;248(5):763-776. doi:10.1097/SLA.0b013e31818702f4

19. Farag YM, Gaballa MR. Diabesity: an overview of a rising epidemic. Nephrol Dialysis Transplant. 2010;26(1):28-35. doi:10.1093/ndt/gfq576

20. Gearhardt AN, Corbin WR, Brownell KD. Preliminary validation of the Yale food addiction scale. Appetite. 2009;52(2):430-436. doi:10.1016/j.appet.2008.12.003

21. VanderBroek-Stice L, Stojek MK, Beach SR, MacKillop J. Multidimensional assessment of impulsivity in relation to obesity and food addiction. Appetite. 2017;112:59-68. doi:10.1016/j.appet. 2017.01.009

22. NVivo qualitative data analysis software; QSR International Pty Ltd. Version 11, 2015.

23. Saldana J. The Coding Manual for Qualitative Researchers. SAGE Publications Ltd; London, 2016.

24. Pope C, Ziebland S, Mays N. Qualitative research in health care. Analysing Qualitative Data. BMJ. 2000;320(7227):114-116.

25. Vanderlee L. McCrory C, Hammond D. Awareness and Knowledge of Recommendations from Canada's Food Guide. Can J Diet Pract Res. 2015;76(3): 146-149.

26. Jump rope for heart: heart and stroke foundation. Available from: http://support.heartandstroke.ca/site/PageServer?pagename=jump17_ home. Accessed March 4, 2015.

27. 20/20 challenge: run 4 change. Available from: http://www.run4ch ange.net/2020-challenge/. Accessed March 4, 2015.

28. Rizvi SL, Dimeff LA, Skutch J, Carroll D, Linehan MM. A pilot study of the DBT coach: an interactive mobile phone application for individuals with borderline personality disorder and substance use disorder. Behav Ther. 2011;42(4):589-600. doi:10.1016/j.beth.2011.01.003

29. Hannon TS, Rao G, Arslanian SA. Childhood obesity and type 2 diabetes mellitus. Pediatrics. 2005;116(2):473-480. doi:10.1542/peds.2004-2536

30. Ebbeling CB, Pawlak DB, Ludwig DS. Childhood obesity: publichealth crisis, common sense cure. Lancet. 2002;360(9331):473-482. doi:10.1016/S0140-6736(02)09678-2

31. Davis JN, Ventura EE, Tung A et al. Effects of a randomized maintenance intervention on adiposity and metabolic risk factors in overweight minority adolescents. Pediatric Obesity. 2012;7(1):16-27.

32. Hamdy O, Carver C. The Why WAIT program: improving clinical outcomes through weight management in type 2 diabetes. Curr Diab Rep. 2008;8(5):413-420.

33. Gillies CL, Abrams KR, Lambert PC, et al. Pharmacological and lifestyle interventions to prevent or delay type 2 diabetes in people with impaired glucose tolerance: systematic review and meta-analysis. Bmj. 2007;334(7588):299. doi:10.1136/bmj.39063.689375.55
34. Ackermann RT, Finch EA, Caffrey HM, Lipscomb ER, Hays LM, Saha C. Long-term effects of a community-based lifestyle intervention to prevent type 2 diabetes: the DEPLOY extension pilot study. Chronic Illn. 2011;7(4):279-290. doi:10.1177/1742395311407532

35. Tuomilehto J, Lindström J, Eriksson JG, et al. Prevention of type 2 diabetes mellitus by changes in lifestyle among subjects with impaired glucose tolerance. N Engl J Med. 2001;344(18):13431350. doi:10.1056/NEJM200105033441801

36. Yeh MC, Heo M, Suchday S, et al. Translation of the diabetes prevention program for diabetes risk reduction in Chinese immigrants in New York City. Diabetic Med. 2016;33(4):547-551. doi:10.1111/dme.12848

37. Vincent D, McEwen MM, Hepworth JT, Stump CS. The effects of a community-based, culturally tailored diabetes prevention intervention for high-risk adults of Mexican descent. Diabetes Educ. 2014;40 (2):202-213. doi:10.1177/0145721714521020

38. Panagiotopoulos C, Hadjiyannakis S, Henderson M. Type 2 Diabetes in Children and Adolescents. Can J Diabetes. 2018;42:S247-S254

39. Crandall JP, Knowler WC, Kahn SE, et al. The prevention of type 2 diabetes. Nature Clin Pract Endocrinol Metab. 2008;4(7):382. doi: $10.1038 /$ ncpendmet 0843

40. Libman IM, Arslanian SA. Prevention and treatment of type 2 diabetes in youth. Horm Res Paediatr. 2007;67(1):22-34. doi:10.1159/000095981

41. Hingle MD, Turner T, Kutob R, et al. The EPIC Kids Study: a randomized family-focused YMCA-based intervention to prevent type 2 diabetes in at-risk youth. BMC Public Health. 2015;15 (1):1253. doi:10.1186/s12889-015-2595-3

42. Flynn M. Reducing obesity and related chronic disease risk in children and youth: a synthesis of the evidence with'best practice'recommendations. Int J Obes. 2008;32(S1-S2):S14-S.

43. Pinzon-Perez H, Kotkin-Jaszi S, Perez MA. Childhood diabesity: international applications for health education and health policy. Global J Health Educ Promotion. 2010;13:1.

44. Barlow S. Expert committee recommendations regarding the prevention, assessment, and treatment of child and adolescent overweight and obesity: summary report. Pediatrics. 2007;120:164-192. doi:10.1542/peds.2007-2329C

45. Golan M, Crow S. Parents are key players in the prevention and treatment of weight-related problems. Nutr Rev. 2004;62(1):39-50. doi:10.1111/j.1753-4887.2004.tb00005.x

46. Davidson K, Vidgen H. Why do parents enrol in a childhood obesity management program?: a qualitative study with parents of overweight and obese children. BMC Public Health. 2017;17(1):159. doi:10.1186/s12889-017-4085-2

47. Eyler AA, Nguyen L, Kong J, Yan Y, Brownson R. Patterns and predictors of enactment of state childhood obesity legislation in the United States: 2006-2009. Am J Public Health. 2012;102(12):22942302. doi:10.2105/AJPH.2012.300763

48. Boehmer TK, Luke DA, Haire-Joshu DL, Bates HS, Brownson RC. Preventing childhood obesity through state policy: predictors of bill enactment. Am J Prev Med. 2008;34(4):333-340. doi:10.1016/j. amepre.2008.01.003

49. Rutkow L, Jones-Smith J, Walters HJ, O’Hara M, Bleich SN. What motivates stakeholder groups to focus on childhood obesity prevention policies? J Childhood Obesity. 2016. doi:10.21767/2572-5394.100007

50. Bray J, Collins C, Morgan P, Burrows T. Effectiveness of parentcentred interventions for the prevention and treatment of childhood overweight and obesity in community settings: a systematic review. JBI Database Syst Rev Implementation Rep. 2010;8(16):1-12. doi:10.11124/01938924-201008161-00003

51. Okely AD, Collins CE, Morgan PJ, et al. Multi-site randomized controlled trial of a child-centered physical activity program, a parent-centered dietary-modification program, or both in overweight children: the HIKCUPS study. J Pediatr. 2010;157(3):388-94. e1. doi:10.1016/j.jpeds.2010.03.028 
52. van Esch SC, Cornel MC, Geelhoed-Duijvestijn PH, Snoek FJ. Family communication as strategy in diabetes prevention: an observational study in families with Dutch and Surinamese South-Asian ancestry. Patient Educ Couns. 2012;87(1):23-29. doi:10.1016/j.pec.2011.07.025

53. Ofori SN, Unachukwu CN. Holistic approach to prevention and management of type 2 diabetes mellitus in a family setting. Diabetes Metab Syndrome Obesity. 2014;7:159. doi:10.2147/DMSO

54. Summerbell CD, Waters E, Edmunds L, Kelly S, Brown T, Campbell KJ. Interventions for preventing obesity in children. Cochrane Database Syst Rev. 2005;3:3.

55. O'Dea JA. School-based health education strategies for the improvement of body image and prevention of eating problems: an overview of safe and successful interventions. Health Educ. 2005;105(1):1133. doi:10.1108/09654280510572277

56. Walker L, Hill AJ. Obesity: the role of child mental health services. Child Adolesc Ment Health. 2009;14(3):114-120. doi:10.1111/ camh.2009.14.issue-3

57. Wright N, Groisman-Perelstein A, Wylie-Rosett J, Vernon N, Diamantis P, Isasi C. A lifestyle assessment and intervention tool for pediatric weight management: the HABITS questionnaire. $J$ Human Nutr Diet. 2011;24(1):96-100. doi:10.1111/j.1365-277X. 2010.01126.x
58. Varni JW, Burwinkle TM, Seid M. The PedsQL ${ }^{\mathrm{TM}}$ as a pediatric patient-reported outcome: reliability and validity of the PedsQL ${ }^{\mathrm{TM}}$ measurement model in 25,000 children. Expert Rev Pharmacoecon Outcomes Res. 2005;5(6):705-719. doi:10.1586/14737167.5.6.705

59. Byrne DG, Davenport S, Mazanov J. Profiles of adolescent stress: the development of the adolescent stress questionnaire (ASQ). J Adolesc. 2007;30(3):393-416. doi:10.1016/j.adolescence.2006.04.004

60. Wardle J, Guthrie CA, Sanderson S, Rapoport L. Development of the children's eating behaviour questionnaire. J Child Psychol Psychiatry Allied Disciplines. 2001;42(7):963-970. doi:10.1111/jcpp.2001.42. issue-7

61. Navarro V. What we mean by social determinants of health. Int $J$ Health Serv. 2009;39(3):423-441. doi:10.2190/HS.39.3.a

62. Ordovas JM, Ferguson LR, Tai ES, Mathers JC. Personalised nutrition and health. Bmj. 2018;361:bmj.k2173. doi:10.1136/bmj.k2173

63. Evangelatos N, Satyamoorthy K, Brand A. Personalized health in a public health perspective. Int J Public Health. 2018;63(4):433-434. doi:10.1007/s00038-017-1055-5

\section{Publish your work in this journal}

Adolescent Health, Medicine and Therapeutics is an international, peer-reviewed, open access journal focusing on health, pathology, and treatment issues specific to the adolescent age group. All aspects of health maintenance, preventative measures and disease treatmen interventions are addressed within the journal and practitioners from all disciplines are invited to submit their work as well as healthcare researchers and patient support groups. The manuscript management system is completely online and includes a very quick and fair peerreview system. Visit http://www.dovepress.com/testimonials.php to read real quotes from published authors. 